\title{
Strategies of HIV Prevention in Low and Middle-Income Countries
}

\author{
Annabel Desgrées du Loû ${ }^{*}, 1$, Sarah Memmi ${ }^{1}$ and Joanna Orne-Gliemann ${ }^{2}$ \\ ${ }^{I}$ CEPED, UMR 196 Université Paris Descartes -INED-IRD, Paris, France \\ ${ }^{2}$ Institut de Santé Publique Epidémiologie Développement (ISPED), Université Victor Segalen Bordeaux 2, Bordeaux, \\ France
}

\begin{abstract}
The number of people newly infected with HIV is still very high in low and middle-income countries. In these countries, the HIV epidemic is dramatically disrupting both their population structure and economic situation. There is an urgent need to reinforce strategies to prevent HIV transmission. Despite certain successes, HIV prevention strategies have not yet been sufficient to significantly limit HIV propagation. New strategies of HIV prevention have been explored. If certain HIV prevention tools have shown some efficacy, others are still under study. This paper reviews what is known about "traditional" HIV prevention strategies and what has been published about the new strategies for HIV prevention since the early 1990s. For increased efficacy, HIV prevention efforts should be tailored to the socio-cultural and economic contexts, the local type of epidemic and the needs of local population.
\end{abstract}

Keywords: HIV prevention, low and middle-income countries, acceptability, safety, efficacy, treatment.

At the global level, the prevalence of HIV infection (proportion of individuals infected with HIV among the general population) appears to have stabilized in recent years. Still, in 2008, it was estimated that 2.7 million new HIV infections occurred worldwide, $90 \%$ of which were in low and middle-income countries [1]. The total number of people living with HIV was estimated at 33.4 million in 2008, most of whom were living in developing countries. Low and middle-income countries are not only the most affected by HIV/AIDS, but they are also facing enormous constraints in mitigating the impact of this epidemic.

Over the past decade, the international community has made substantial, though still insufficient, efforts to improve worldwide access to HIV/AIDS treatment, i.e. antiretrovirals. However in $2008,60 \%$ of the population eligible for antiretroviral therapy in resource-limited countries still didn't access it [2]. The total number of people knowing their HIV status is growing. Thus overall, the number of antiretroviral drugs to be distributed is inexorably increasing worldwide [3]. In low-income countries, the financial resources dedicated to health are limited. This is why even in the era of HIV/AIDS treatment, the prevention of HIV infection remains a worldwide public health priority [4] and is also an economic challenge [5].

More than 20 years after the onset of the HIV/AIDS epidemic, it is estimated that each day, 7400 persons are newly infected by HIV, $96 \%$ of them live in resource-limited countries [1]. The high rates of new HIV infections observed today largely result from the failure to use the available and effective HIV prevention strategies and tools, and from the poor coverage of HIV prevention programmes in these

*Address correspondence to this author at the CEPED, 19 rue Jacob 75006 , Paris, France; Tel : 00331789498 70; Fax: 00331789498 79;

E-mail: annabel.desgrees@ird.fr countries. According to UNAIDS, HIV prevention services were only reaching $20 \%$ of people in need in 2005 [6].

In this paper, we first review the scientific literature documenting the HIV prevention strategies developed and implemented over the past decades, their successes and their limits. We reviewed the published scientific literature documenting past and new HIV prevention strategies, from the early 1990 s to december 2009 . We focused on the case of low and middle-income countries, the most severely affected by the HIV/Aids epidemic. We consulted the Medline and Science Direct databases, using the research terms "HIV preventions", "low and middle income countries" or "strategies of prevention" or "fight against AIDS". We also consulted the websites of international institutions such as the World Health Organisation, UNAIDS or UNICEF.

We then outline the new approaches to HIV prevention that are currently being explored, those reporting interesting efficacy results, and others still under study.

\section{SUCCESSES AND LIMITS OF "TRADITIONAL" HIV PREVENTION STRATEGIES}

HIV can be transmitted through sexual intercourse or needle/syringe sharing with a person who is HIV-infected, or through transfusions of infected blood. HIV can also be transmitted from an HIV-infected woman to her infant during pregnancy, labour and delivery, as well as through breastfeeding after birth. HIV epidemics and patterns of HIV transmission vary across regions and countries. In subSaharan Africa, the HIV epidemic is largely fuelled by heterosexual transmission and mother-to-child transmission of HIV. In most Asian countries, HIV infection is also predominant among injecting-drug users: for example in China, in 2006, almost $50 \%$ of people living with HIV were infected through the use of contaminated injecting equipment [6]. However, in China like in many parts of Asia 
the epidemic is steadily expanding into lower-risk populations through transmission to the sexual partners of those most at risk [1]. In Latin America, the primary mode of HIV transmission is currently among men who have sex with men [1]. Thus overall it has now been widely acknowledged that HIV prevention approaches need to be adapted and tailored to the various and country-specific epidemics [7].

\subsection{Preventing Sexual Transmission of HIV}

\section{Promoting Male Condoms has Contributed to Prevent HIV} but is Not Adapted to All Couple Relationships

The male condom, if consistently used, reduces the risk of heterosexual transmission of HIV by $80 \%$ [8]. Male condoms also have a low production and distribution cost and thus have been considered as one of the most costeffective HIV prevention tools [5]. HIV prevention campaigns focused on the prevention of sexual risks have increased the use of male condoms over the past decades [9] and reduced the number of sexual partners [10]. But the coverage of male condom use is still insufficient to stop the progression of the HIV epidemic, especially in low and medium-resource countries. There are indeed several cultural and religious barriers to the wide scale use of male condoms [11]. Moreover condom use within stable relationships has long been shown to be complex [12], as it may be perceived as a sign of infidelity and mistrust [13, 14]. Moreover, consistent condom use is not reconcilable with procreation. Thus within stable relationships, condom use must be selective and therefore remains imperfect. Yet several studies have reported that a large proportion of HIV infections occur in the context of stable relationships [15]. Demographic and Health data from Burkina Faso, Cameroon, Ghana, Kenya and Tanzania has shown that at least two-thirds of HIV-infected heterosexual couples are serodiscordant (one partner is HIV-infected, the other is HIV-negative). But less than $30 \%$ of these couples report using a male condom at last sexual intercourse, even when aware of their respective HIV status [16].

\section{The Female Condom: A Very Low Coverage}

Female condoms, like male condoms, are a protection against sexually transmitted infections and unwanted pregnancies. As this device can be used and handled by women, it first raised many hopes: promoting the use of female condoms would provide women with the possibility of protecting themselves during sexual intercourse, an opportunity that they don't always have in the context of male-dominated relationships. The benefits of female condoms have been proved [17]. Studies have shown that the use of female condoms has increased the proportion of protected sexual intercourse without reducing the use of male condoms [18] as women use both condoms interchangeably [19]. However the use of female condoms faces similar challenges to male condoms. It is not $100 \%$ efficient: a multisite study showed that probably due to incorrect use of female condoms, several women got pregnant [20]. Female condoms also require the involvement of men: a study conducted in Zambia showed that if women were those initiating dialogue around condoms, these were used after joint decision-making from both couple members [21]. And finally, female condoms are 10 times more costly than male condoms; they are also more conspicuous and more difficult to handle [22]. As a result overall, female condoms are not largely distributed, even in high prevalence countries.

\section{Behaviour Change: The ABC Controversy}

The ABC strategy ("Abstinence, Be faithful, Use a Condom") aims at preventing high-risk behaviours for HIV infection. It promotes abstinence until marriage, mutual fidelity after marriage and the use of condoms for people who would be unable to follow these two recommendations [23]. Several American institutions and African governments adopted this strategy early in the HIV epidemic [24]. In the late 1980 s, to fight the high national prevalence of HIV, the Ugandan president Museveni encouraged young people to delay their sexual debut or to return back to abstinence, while promoting the use of condoms in the rest of the population. The prevalence of HIV/AIDS in Uganda declined by $10 \%$ from $15 \%$ in 1990 to $5 \%$ in 2001 [25]. Nevertheless, the role and impact of the ABC programme in this decline can be questioned. And indeed the decrease in the number of HIV/AIDS cases in Uganda may more likely be associated with an increased use of condoms and a lower number of sexual partners [26].

At an international level, this ABC strategy has also been highly controversial. It has been accused of polarising prevention efforts on abstinence and fidelity to the detriment of measures promoting education, woman empowerment or access to antiretroviral therapy [27]. It was also underlined that it was moralising strategy, which could stigmatise sexual intercourse outside of marriage, discourage adolescent women from discussing their sexuality and prevent them from accessing sexual and reproductive health services [28]. Finally, it has been argued that abstinence until marriage and fidelity are no guarantee of an individual's safety: one always remains dependent on one's partner's fidelity, which cannot be controlled. Women thus can be easily exposed to the risk of HIV infection within their couple, in particular in certain socioeconomic and cultural contexts where male infidelity is frequent $[25,29]$.

During the 2004 Bangkok conference, an alternative to the ABC approach was discussed: the CNN strategy (Condom, Needle exchange, Negotiation skills): this approach takes into account homosexuals, sex workers and drug-users - population groups which had been ignored within the ABC approach - promotes condom use, negotiation within the couple and the safe exchange of needles [29].

\subsection{Insufficient Prevention of Blood Transmission of HIV}

Worldwide, the use of contaminated injecting equipment accounts for one third of new infections outside Sub-Saharan Africa [30]. Drug injection is particularly prevalent among 15-24 year olds [31;32]. HIV prevention programmes targeted towards injecting drug-users are efficient but they are insufficiently developed [33]. Several studies have shown that the use of injectable drugs was associated with high-risk sexual behaviours [34]. Despite a high number of HIV/AIDS cases among injecting drug-users, few have access to antiretroviral therapy $[35 ; 36]$. Targeted and 
adapted HIV prevention programmes within this population are therefore crucial [37].

The number of HIV/AIDS cases due to blood transfusion is little documented. Yet it is estimated that millions of patients are unable to receive safe blood when in need. Two studies conducted in Côte d'Ivoire and Burkina Faso showed that the risk of HIV infection after a blood transfusion remains substantial [38, 39]. Between $1^{\text {st }}$ January 1998 and $31^{\text {st }}$ December 1999, at the Ouagadougou Hospital, 3.5\% of the transfused samples, $80 \%$ of which were destined for the paediatric ward, were infected by HIV. In addition, as shown recently in Niger, the national availability of blood was low while at the same time transfusion needs were increasing [40]. Finally, according to UNAIDS, while 91 countries have taken steps to secure the blood donation, 34 have not yet reached the quality goals and 67 countries are unable to provide an indicator for this topic [6].

\subsection{Preventing Mother-to-Child Transmission of HIV: Encouraging Progress}

\section{Progress and Current Challenges}

In 2008, every day an estimated 1200 children under 15 years old were newly infected by HIV, $90 \%$ of whom lived in sub-Saharan Africa [1]. Most of these children were infected by mother-to-child transmission of HIV, a form of transmission, which can be prevented but remains a challenge for most resource-limited settings [41, 42]. Over the past 15 years, a certain number of antiretroviral regimens were shown to be safe, efficient, cost-effective and feasible in reducing the risk of mother-to-child transmission of HIV. The implementation of these prophylactic antiretroviral regimens has improved over the past few years. In 2008, in low and middle-income countries, $45 \%$ of pregnant women diagnosed with HIV received antiretroviral therapy for the prevention of mother-to-child transmission, compared to $9 \%$ in $2004[6,43]$. However the coverage of this HIV prevention strategy is still far from optimal in most resourcelimited countries. The main obstacles to preventing motherto-child transmission of HIV in these settings have been related to the limited access to prenatal HIV counselling and testing services and to the complexity of preventing HIV transmission through breastmilk. The latest and simplified recommendations on the use of antiretroviral drugs for treating pregnant women and preventing HIV infection in infants, made available in November 2009, should contribute to improving the coverage and efficacy of prevention of mother-to-child transmission of HIV interventions.

\section{Improving Access to Prenatal HIV Counselling and Testing}

The first step in preventing mother-to-child transmission of HIV is to provide HIV counselling and testing services to pregnant women. Yet in 2008, only $21 \%$ of pregnant women were tested for HIV in low and middle income countries [43]. In many settings, prenatal HIV counselling and testing are provided to pregnant women in addition to other prenatal services - the women needing to "opt-in" for this intervention. Pregnant women are offered HIV testing after a pre-test HIV counselling session and are requested to provide an informed and written consent before being tested. Women who accept HIV testing are tested on the same day and advised to return for their test results and a post-test HIV counselling session between a few days to two weeks later. In this context, a large proportion of pregnant women who are offered HIV testing in the end decline the test or do not return to collect their test results. There are several explanations for these drop-outs, such as the women's reticence at requesting a service which is not part of standard care, the fear of learning their HIV status, the feeling of not being "ready" to receive the test results, or for certain women the need to secure their partner's approval [44]. For the past few years, in response to the urgent need to increase the coverage of HIV counselling and testing [45], for pregnant women and the overall population, the World Health Organisation has promoted a provider-initiated approach to HIV counselling and testing [46]. Prenatal HIV counselling and testing is now increasingly promoted as a routine part of antenatal care: blood sampling for HIV testing is systematically suggested to a pregnant woman attending prenatal care, and performed unless she explicitly refuses HIV testing, i.e. an opt-out approach [46]. In Zimbabwe, this opt out approach was shown to be acceptable [47] and efficient with prenatal testing rates increasing from $65 \%$ to $99 \%$ in the first six months where a policy on provider-initiated testing and counselling was implemented [48]. Shifting to this opt-out approach, based on the pregnancy care providers' initiative, leads to a higher proportion of pregnancies in which HIV testing is offered and actively recommended.

As a safety net, to ensure that the maximum number of pregnant women are informed of their HIV status, several researchers have documented the potential of HIV testing in the labour ward [49]. This strategy is however suboptimal as women in labour, i.e. in pain or in distress, are not likely to be fully receptive to adequate HIV counselling or capable of informed consent and decision-making to HIV testing [50].

Moreover, for many years, research has shown that barriers to the acceptability of prenatal HIV counselling and testing were not only systemic but also related to the social and family context pregnant women live in. Many pregnant women report needing to first consult their partner to obtain his to approval before undertaking HIV testing [51, 52], even in the context of an opt-out approach to prenatal HIV testing [53]. In spite of repeated recommendations within the international community [54] few published studies have explored the interest of a couple approach to prenatal HIV counselling and testing, although the available data is edifying. In Zambia and Kenya, where pregnant women were offered individual or couple HIV counselling, couple HIV counselling improved the uptake of HIV testing, antiretroviral prophylaxis and alternatives to prolonged and mixed breastfeeding, and no increased risk of adverse social events was reported compared to individual counselling [55, 56].

\section{The Challenge of Preventing Postnatal Transmission of HIV}

Once pregnant women have been counselled and tested for HIV, identified as $\mathrm{HIV}$-infected, provided with an appropriate antiretroviral prophylaxis for preventing peripartum transmission of HIV, the challenge of preventing HIV through breastfeeding still remains. In the absence of any targeted postnatal intervention, breastfeeding is 
responsible for $8.9 \mathrm{HIV}$ infections per 100 child-years of breastfeeding and accounts for $40 \%$ of paediatric HIV infections $[57,58]$. Three main factors seem to influence the risk of HIV transmission through breastfeeding. First, maternal health: the risk of postnatal HIV transmission is 3 to 10 times higher among women who are more seriously ill, with CD4 count $<200$ cells $/ \mathrm{ml}$ compared to women above this threshold [59]. Second, the duration of breastfeeding: the longer the breastfeeding lasts, the higher the resulting risk of postnatal transmission of HIV [60]. And finally, the pattern of breastfeeding: the practice of exclusive breastfeeding during the first months of life is associated with a lower risk of postnatal HIV transmission than the practice of mixing breastfeeding with other fluids or solids [61].

Until recently, most research focused on the last two factors, pattern and duration. Given the necessary support, formula feeding and early breastfeeding cessation (prior six months of life) can reduce and even eliminate the risk of postnatal HIV transmission [62]. However the health risks associated with unsafe artificial feeding or the social risks associated with not breastfeeding are problematic for many women in resource-limited settings [63, 64].

In the context of increasing access to antiretroviral therapy, research has more recently focused on alternative interventions to ensure safer breastfeeding based on antiretroviral treatments. Antiretroviral drugs can be given to breastfed infants as prophylaxis against HIV exposure [6567], but need to be administered during the whole breastfeeding period to effectively prevent the postnatal risk of HIV transmission [68, 69]. Maternal antiretroviral therapy, which rapidly and continuously reduces the viral load in plasma and breastmilk [70,71], also has the potential to reduce the risk of HIV transmission during breastfeeding. Preliminary results from the ongoing Kesho Bora study have shown that the risk of postnatal HIV transmission was reduced by $40 \%$ among infants whose mothers received antiretroviral therapy from late in pregnancy until six months into breastfeeding, compared to others who were administered a short course of drugs that ended at delivery [72]. They also showed that this antiretroviral therapy strategy was more efficient among women with CD4 counts between 200 and $350 \mathrm{cells} / \mathrm{ml}$. Although short to mediumterm potential adverse effects and toxicities of exposure to antiretroviral therapy exist for infants, these seem to be largely outweighed by the immense benefits in terms of preventing HIV transmission [73]. As summarised within a recent review paper [42], most recent research results argue in favour of making HAART (highly active antiretroviral therapy) available to all HIV-infected pregnant women in resource-limited settings, irrespective of their CD4 count or clinical stage, both for the prevention of mother-to-child transmission of HIV and for their own health.

In the recently released WHO guidelines on the use of antiretroviral drugs for treating pregnant women and preventing HIV infection in infants, two options of similar efficacy are now offered for pregnant women with CD4 count above the $350 \mathrm{CD} 4$ treatment eligibility threshold [74]. Option A consists in providing maternal zidovudine prophylaxis from the second trimester of pregnancy until delivery, followed by daily oral nevirapine to the breastfed infant until all breastfeeding has ceased. Option B consists of the provision of maternal triple antiretroviral prophylaxis (as per ART for treatment) starting from the second trimester of pregnancy until all exposure to breast milk has ended.

\section{NEW TRACKS FOR HIV PREVENTION}

\subsection{Enhanced HIV Testing Strategies: Opt-Out, Rapid and Couple-Centre HIV Testing}

HIV testing is a cornerstone of HIV prevention: the knowledge of one's HIV status is an important incentive to adopt appropriate behaviours to prevent HIV transmission if HIV-infected [75]. Yet, even more than the coverage of prenatal HIV counselling and testing, the coverage of HIV testing for the general population remains largely insufficient worldwide. The latest data indicates that less than $40 \%$ of people living with HIV know their status [1]. This lack of knowledge is a major obstacle to HIV prevention [76]. In order to increase the proportion of people tested for HIV, HIV testing strategies have evolved over the past decade.

Within a provider-initiated HIV counselling and testing approach [77], HIV counselling services are simplified (reduced pre-test HIV counselling and strengthened post-test HIV counselling services) [78]. A study conducted in Uganda evaluated the acceptability and efficacy of this optout approach to HIV testing among hospital patients and their family members [79]. It showed that $98 \%$ of patients accepted HIV testing, among whom $81 \%$ were tested for the first time. In addition, community-based strategies for HIV counselling testing, outside the health centre, such as mobile clinics or door-to-door (home-based) HIV testing have recently been advocated and shown to be effective in Uganda [80]. Regardless of the location of or approach to HIV counselling and testing, ensuring the quality and confidentiality of HIV counselling services remains paramount.

To increase the rate of patients returning to collect their HIV test results, rapid HIV testing has been promoted in resource-limited settings since the early 2000s. Rapid HIV tests take a few minutes and results can be given to the patient the same day. This HIV testing strategy is highly feasible in resource-limited settings, as it only requires basic laboratory equipment [77]. The acceptability of rapid HIV testing is high, although certain studies have shown that some patients prefer to have time before being informed of their test results [81].

Finally, several studies have explored the benefits of offering HIV counselling and testing to couples [82]. A large proportion of patients refuse HIV testing because they fear their partner's reactions. Counselling both partners together is likely to reduce this fear and the mutual knowledge of their HIV status contributes to facilitate HIV prevention within the couple. Couples who are informed that they are serodiscordant may receive more appropriate support. And it has been shown that the disclosure of HIV tests results within the couple rarely has negative consequences $[56,83]$.

\subsection{Diversifying Strategies to Reduce the Sexual Transmission of HIV}

\section{Microbicides: A Wrong Good Idea?}

Microbicides are chemical products such as gels, creams, films or suppositories which are inserted in the vagina before 
sexual intercourse and may prevent sexually transmitted infections. Microbicides have raised many hopes over the last decade in the sense that, as female condoms, they would be a female-controlled HIV prevention method that women could use without the need for their partner's approval. However the results of the various clinical trials conducted so far are not conclusive. In 2002, a study conducted among 900 sex workers clearly demonstrated that the microbicide tested did not significantly prevent HIV transmission among the populations at risk [84]. More recently, several studies had to be interrupted because of safety or inefficacy issues [85]. The repeated use of microbicides could indeed be toxic and increase the risk of HIV infection. The conclusions of the recently conducted Pro2000 placebo controlled trial, which involved 9385 women in four African countries, indicate that the HIV prevention gel Pro2000 was ineffective in reducing the risk of HIV infection among women [86]. Continuing efforts to develop effective products are now focusing on microbicides which contain antiretroviral drugs.

\section{Positive Prevention or the Involvement of People Living with HIV/AIDS}

HIV prevention has mainly been focused on HIVnegative individuals [87]. Yet, HIV-infected people are the vectors of HIV transmission and as such should be key actors of HIV prevention programmes. When aware of their HIV status and provided with the appropriate treatment and information, people living with HIV/AIDS can become key actors in the fight against HIV/AIDS [75]. This concept of "positive prevention" is based on the "virtuous" circle that is initiated when access to treatment is facilitated and associated preventive programmes are supported.

\section{Male Circumcision}

Several randomised trials conducted in South Africa, Uganda and Kenya have shown that male circumcision performed by skilled health professionals reduces the risk of HIV transmission from woman to man by $60 \%$ [88-90]. These study results have raised both great hopes and concerns: Bertran Auvert compared male circumcision to a "highly efficient vaccine" [88], but the feasibility, acceptability and effectiveness of large-scale male circumcision programmes is yet to be evaluated. It is unknown whether men will easily accept to be circumcised in a context where condom use is still so complex [91]; or whether circumcised men will feel totally protected against HIV and abandon condom use. The preliminary results of a recent study conducted in Uganda among $922 \mathrm{HIV}$-infected men aged between 15 and 49, half of whom were circumcised, showed a higher HIV prevalence among the female partners of these circumcised men (18\%) compared to the control group (12\%) [92]. This can be explained by the fact that circumcised men reported resuming unprotected sexual course early, whereas they had been advised to abstain until complete healing. The study was thus interrupted [92]. Learning from this experience and in order to prevent further adverse events related to the misinterpretation of the effect of male circumcision and to encourage the scaling-up of male circumcision for HIV prevention, WHO recently produced new recommendations [93] i.e. to integrate male circumcision within a comprehensive package of HIV prevention initiatives, involve men's partners [94], strengthen health care services, train health care workers to practice circumcision, increase access to circumcision services and develop research in that field.

\subsection{Antiretroviral Therapy for HIV Prevention: A Strategy for the Future?}

In 2005, a study conducted in Spain among more than 350 heterosexual serodiscordant couples showed that HAART, by decreasing the viral load, reduced or even suppressed the risk of HIV transmission [95]. More recently, the results of a mathematical model suggested that universal HIV testing and highly active antiretroviral therapy delivered to all HIV-infected individuals immediately after HIV diagnosis, regardless of the stage of their infection, could have a major effect on the evolution of the HIV pandemic, by rapidly reducing HIV transmission to nearly zero [96]. This hypothesis has triggered a rich debate within the international scientific community and several questions have been raised: how realistic and feasible is it to aim for universal HIV testing when currently more than $80 \%$ of people in sub-Saharan Africa, the most affected region in the world, have not yet been tested? How can we provide universal access to highly active antiretroviral therapy in resource-limited settings where most people who are eligible for treatment according to current WHO guidelines still do not access it [97]? Research is urgently needed to evaluate the relevance and effectiveness of such an approach to highly active antiretroviral therapy and HIV prevention [98, 99]. Several intervention trials have started or are currently planned in order to evaluate: whether HIV incidence is indeed lower within populations accessing universal HIV testing and highly active antiretroviral therapy for all HIVinfected individuals, whether such an intervention is feasible or whether it is acceptable to provide highly active antiretroviral therapy to people who do not need it for their own health.

\subsection{Pre and Post-Exposure Prophylaxis}

Pre-exposure prophylaxis consists in providing highly active antiretroviral therapy to individuals before potential risk behaviour in order to reduce the risk of infection if exposed to HIV. Post-exposure prophylaxis is the provision of highly active antiretroviral therapy after risk behaviour. Research has shown that both strategies have the potential to reduce the incidence of HIV infection [100].

Within resource-limited countries, pre-exposure prophylaxis among individuals with sexual behaviours at risk does not seem to be an efficient or relevant strategy $[101,102]$. Indeed, it could increase sexual risk taking and impact negatively on the incidence of other sexually transmitted infections. The acceptability of this approach is also problematic [103] and currently, most health institutions are not prepared to handle the social, cultural and medical issues raised by pre-exposure prophylaxis.

Post-exposure prophylaxis is mainly addressed to health care professionals having accidentally been in contact with HIV-infected blood. But even for this particular case of workplace injuries, it is still not widely available within resource-limited settings. A study conducted within two hospitals in Morocco showed that $50 \%$ of health care 
workers ignored the basic procedures to inactivate the virus if exposed to infected blood such as the use of bleach or alcohol [104]. Moreover, although frequent, workplace injuries are largely underreported. Health care workers are insufficiently informed and their knowledge of institutional transmission of HIV is poor. As a result, health care workers face a double burden: they are being increasingly mobilised to respond to the HIV/AIDS epidemic and are also being increasingly infected and affected by HIV. It is therefore crucial to further improve workplace safety conditions for health care workers in order to ensure their capacity to respond to HIV/AIDS care needs [105].

\subsection{An HIV Vaccine?}

For several years, the most awaited HIV prevention strategy has been a potential vaccine. Under study for more than two decades, the HIV prevention vaccine is no longer an impossible method, but it is still "to come". Very recently, the first results of the RV144 study provided great hope for demonstrating the efficacy of a candidate vaccine [106]. The RV144 trial tested the combination of two vaccines, ALVAC-HIV (prime) and AIDSVAX (boost) according to the Prime-Boost strategy, among more than 16 000 HIV-negative volunteers in Thailand. According to the first results announced by the trial investigators, the primeboost combination lowered the rate of HIV infection by 31.2 percent compared to placebo [107]. Although these were the first positive HIV vaccine results ever reported, they have been recently questioned by several scientific groups. First, regarding the choice of announcing a $31.2 \%$ efficacy, using a modified intention-to-treat analysis, instead of a $26.4 \%$ $(\mathrm{P}=0.08)$ and $26.2 \%(\mathrm{P}=0.16)$ efficacy using intention-totreat and per-protocol analyses, respectively [108]. Second, regarding the fact that despite its possible effect on the acquisition of HIV-1 infection, the vaccine did not have any effect on the early HIV-1 viral load or CD4+ T-cell counts in vaccinated subjects who eventually became infected. Also regarding the duration of the possible vaccine effect, as most of the effect is likely to have occurred during the first year. And finally, regarding the relative contribution of each of the vaccine components to the observed effects. Thus overall, the possible vaccine efficacy observed was modest and indicates that the vaccine regimen studied is unlikely to be a public health control measure for HIV-1 infection, as the authors themselves acknowledge. Despite these limitations, this HIV vaccine study does offer insight for future research.

\section{CONCLUSION}

More than 20 years after the onset of the epidemic, and in spite of an unprecedented scientific, political and community mobilisation, HIV/AIDS is far from being eradicated. New and more efficient highly active antiretroviral therapy regimen are being identified each year and have contributed to decreasing the mortality related to HIV/AIDS, which can now be considered as a chronic disease in many settings. However these treatments remain expensive and access to them in low and middle-income countries is far from satisfying, even in the context of massive international support. HIV prevention thus remains a priority.

HIV prevention strategies considered in the early stages of the epidemic have shown their limits. In the field of the sexual transmission of HIV, the male condom has not been the "magic bullet" so hoped for. Even if the use of male condoms has increased worldwide, it is still largely insufficient to mitigate the epidemic and remains too inconsistent, especially in the context of couple relationships. Female condoms and sexual behaviour changes appear to be difficult to promote at a large scale. Prevention of blood transmission remains insufficiently developed.

The prevention of mother-to-child transmission of HIV, using ARV prophylaxis administered to the mother and the newborn, has registered undeniable successes since 1996. Research and field efforts are still ongoing in order to reduce further the risk of transmission to the child, and to ensure that prevention of mother-to-child transmission of HIV services are accessible to more and more pregnant women worldwide.

Some HIV prevention strategies considered in the early stages of the epidemic and which were shown to be highly effective are still not being implemented or, when implemented, on an insufficient scale (for example substitution treatment for intravenous drug users).

In recent years, several new tracks have been explored to improve the prevention of HIV transmission. Among those that showed encouraging results, we can mention new HIVtesting strategies, that will increase the number of people identified as HIV-infected; male circumcision and antiretroviral therapy as tools to reduce sexual transmission; and the vaccine. But it is expected that these different HIV prevention strategies will have only partial efficacy.

So what seems certain today is that there is no single response to HIV/AIDS: the fight against HIV/AIDS will require a comprehensive set of HIV prevention strategies, which needs to be tailored to the socio-cultural and economic contexts, to the local type of epidemic and to the needs of the local population. And we must not forget that all of these prevention strategies will remain ineffective if they take place in a context of HIV related stigma and discrimination.

\section{REFERENCES}

[1] UNAIDS and WHO. AIDS epidemic update 2009. Geneva: UNAIDS. Available at: http://data.unaids.org/pub/Report/2009/ 2009_epidemic_update_en.pdf. Accessed 6 January 2010.

[2] WHO. Towards universal access: scaling up priority HIV/AIDS interventions in the health sector. Progress Report 2009. Geneva: World Health Organisation. Available at: http://www.who.int/hiv/ pub/tuapr_2009_en.pdf. Accessed 7 January 2010.

[3] Over M. Échec de la prévention: le poids croissant des droits engendrés par l'aide américaine au financement du traitement mondial contre le VIH/SIDA et la voie à suivre. Revue d'économie du développement 2009; 23: 107-144.

[4] Piot P, Bartos M, Larson H, Zewdie D, Mane P. HIV prevention 6 Coming to terms with complexity: a call to action for HIV prevention. Lancet 2008; 372(9641): 845-59.

[5] Marseille E, Morin SF, Collins C, Summers T, Coates T, Kahn JG. Cost-Effectiveness of HIV Prevention in Developing Countries. HIV InSite Knowledge Base Chapter 2002. Available at: http://www.iadb.org/sds/specialprograms/lachealthaccounts/Docum ents/UCLA_Marseille_2002_Cost_effectiveness_prevention_AIDS _developing_countries_en.pdf. Accessed 7 January 2010.

[6] UNAIDS. Report on the global AIDS epidemic 2008. Geneva: UNAIDS. Available at: http://www.unaids.org/en/KnowledgeCe ntre/HIVData/GlobalReport/2008/2008_Global_report.asp. Accessed 7 January 2010. 
[7] Wilson D, Halperin D. Know your epidemic, know your response: a useful approach, if we get it right. Lancet 2008; 372(9637): 4236.

[8] Weller S, Davis K. Condom effectiveness in reducing heterosexual HIV transmission. Cochrane Review 2003. In: The Cochrane Library, Issue 4, 2003. Chichester, UK: John Wiley \& Sons, Ltd. Available at: http://209.85.229.132/search?q=cache:_-hT3RMQA GsJ:www.iglesia.cl/iglesiachile/especiales/weller.doc+Condom+eff ectiveness + in + reducing + heterosexual + HIV + transmission.+ Cochra ne + Review $+2003 \& \mathrm{~cd}=4 \& \mathrm{hl}=$ fr $\& \mathrm{ct}=\mathrm{clnk} \& \mathrm{gl}=$ fr\&client=firefox-a. Accessed 7 January 2010

[9] Cleland J, Ali M. Sexual abstinence, contraception, and condom use by young African women: a secondary analysis of survey data. Lancet 2006; 368:1788-93.

[10] Alonso A, de Irala J. Changes in sexual behaviours to prevent HIV. Lancet 2006; 368: 1749-50.

[11] UNAIDS. The male condom. Best practices collection. 2000. Available at: http://data.unaids.org/Publications/IRC-pub01/jc302tu18-malecondom_fr.pdf

[12] Worth D. Sexual decision-making and AIDS: why condom promotion among vulnerable women is likely to fail. Stud Fam Plan 1989; 20: 297-307.

[13] Chimbiri AM. The condom is an 'intruder' in marriage: evidence from rural Malawi. Soc Sci Med 2007; 64(5): 1102-15.

[14] Desgrées-du-Loû A, Brou H, Tijou-Traoré A, Djohan G, Becquet $\mathrm{R}$, Leroy V. From prenatal HIV testing of the mother to prevention of sexual HIV transmission within the couple. Soc Sci Med 2009; 69: 892-9.

[15] Chomba E, Allen S, Kanweka W, et al. Evolution of Couples' Voluntary Counseling and Testing for HIV in Lusaka, Zambia. J Acquir Immune Defic Syndr 2008; 47(1): 108-15.

[16] De Walque D. Sero-Discordant Couples in Five African Countries: Implications for Prevention Strategies. Popul Dev Rev 2007; 33(3): 501-23.

[17] Feldblum PJ, Kuyoh MA, Bwayo JJ, Omari M, Wong EL, Tweedy $\mathrm{KG}$, et al. Female condom introduction and sexually transmitted infection prevalence: results of a community intervention trial in Kenya. AIDS 2001; 15(8): 1037-44.

[18] Choi KH, Gregorich SE, Anderson K, Grinstead O, Gómez CA. Patterns and predictors of female condom use among ethnically diverse women attending family planning clinics. Sex Transmit Dis 2003; 30(1): 91-8.

[19] Telles Dias PR, Souto K, Page-Shafer K. Long-term female condom use among vulnerable populations in Brazil. AIDS Behav 2006; 10(4 Suppl 7): 67-75.

[20] Farr G, Gabelnick H, Sturgen K, Dorflinger L. Contraceptive efficacy and acceptability of the female condom. Am J Public Health 1994; 84(12): 1960-4.

[21] Agha S. Intention to use the female condom following a massmarketing campaign in Lusaka, Zambia. Am J Public Health 2001; 91(2):307-10.

[22] Artz L, Demand M, Pulley L, Posner SF, Macaluso M. Predictors of difficulty inserting the female condom. Contraception 2002; 65(2): 151-7.

[23] U.S. Department of State. ABC Guidance: Defining the ABC Approach. The President's Emergency Plan for AIDS Relief 2009. Available at: http://www.pepfar.gov/guidance/75837.htm. Accessed 7 January 2010

[24] AIDS charity AVERT. The ABC of HIV prevention. 2009. Available at: http://www.avert.org/abc-hiv.htm. Accessed 7 January 2010.

[25] Murphy EM, Greene ME, Mihailovic A, Olupot-Olupot P. Was the "ABC" Approach (Abstinence, Being Faithful, Using Condoms) Responsible for Uganda's Decline in HIV? PLoS Med 2006; 3(9): 1443-47.

[26] Singh S, Darroch JE, Bankole A. A, B and C in Uganda: The roles of abstinence, monogamy and condom use in HIV decline. Reprod Health Matters 2004; 12(23): 129-35.

[27] Barnett T, Parkhurst J. HIV/AIDS: sex, abstinence, and behaviour change. Lancet Infect Dis 2005; 5(9):590-3

[28] Kaljee L, Mackenzie M, Riel R, et al. Sexual stigma, sexual behaviors, and abstinence among Vietnamese adolescents: implications for risk and protective behaviors for HIV, sexually transmitted infections, and unwanted pregnancy. J Assoc Nurses AIDS Care 2007; 18(2): 48-59.
[29] Sinding SW. Does 'CNN' (Condoms, Needles, Negotiation) Work Better than 'ABC' (Abstinence, Being Faithful and Condom Use) in Attacking the AIDS Epidemic? Int Fam Plan Perspect 2005; 31(1): 38-40.

[30] UNAIDS, 2009. Injecting drug users.Available at: http://www.un aids.org/en/KnowledgeCentre/Resources/FeatureStories/archive/20 09/20090312_MBartosInterview.asp. Accessed 7 January 2010.

[31] Montgomery SB, Hyde J, De Rosa CJ, et al. Gender differences in HIV risk behaviors among young injectors and their social network members. Am J Drug Alcohol Abuse 2002; 28(3): 453-75.

[32] Dolan K, Niven H. A review of HIV prevention among young injecting drug users: A guide for researchers. Harm Reduct J 2005; 2(5): $1-5$.

[33] Van Ameijdene EJ, Coutinho RA. Maximum impact of HIV prevention measures targeted at injecting drug users. AIDS 1998;12(6): 625-33.

[34] Haley N, Roy E, Leclerc P. Réduction des risques et des méfaits, Interventions de prévention efficaces contre le VIH et l'hépatite $\mathrm{C}$ chez les jeunes utilisateurs de drogues par injection. Drogues santé Soc 2003;2(1): 1-15.

[35] Lert F, Kazatchkine M. Antiretroviral HIV treatment and care for injecting drug users: An evidence-based overview. Int J Drug Policy 2007; 18(4):255-61.

[36] Aceijas C, Oppenheimer E, Stimson GV, Ashcroft RE, Matic S, Hickman M. Antiretroviral treatment for injecting drug users in developing and transitional countries 1 year before the end of the "Treating 3 million by 2005. Making it happen. The WHO Strategy" ("3 by 5"). Addiction 2006; 1246-53.

[37] Wood E, Montaner J, Kerr T. Illicit drug addiction, infectious disease spread, and the need for an evidence-based response. Lancet Infect Dis 2008; 8(3):142-3.

[38] Kple-Faget P, Seka Seka J, Akre Dagra P. La transfusion sanguine chez les enfants drépanocytaires au CHU d'Abidjan. Méd Afr Noire 1996; 43(12): 650-3

[39] Ye D, Kam K, Bonkoungou V, Sanou I, Traoré-Ouedraogo R, Sawadogo A. Urgences transfusionnelles et infection à VIH en milieu hospitalier. Arch Pédiatr 2003; 10(6): 549-50.

[40] Ahmed SG, Ibrahim UA, Kagu MB. The burden of HIV and AIDS on blood bank reserves in northeast Nigeria. Trans R Soc Trop Med Hyg 2007; 101(6): 618-20.

[41] Mclntyre J. Maternal Health and HIV. Reprod Health Matters 2005;13(25):129-135.

[42] Becquet R, Ekouevi DK, Arrive E, et al. Universal antiretroviral therapy for pregnant and breastfeeding HIV infected women: Towards the elimination of mother-to-child transmission of HIV-1 in resource limited settings, Clin Infect Dis 2009; 49(12): 1936-45.

[43] De Cock KM, Marum E, MboriNgacha D. A serostatus-based approach to HIV/AIDS prevention and care in Africa. Lancet 2003; 362(9398):1847-9.

[44] UNICEF. Children and AIDS:Fourth Stocktaking Report 2009.USA:UNICEF. Available at:http://www.unicef.org/publicati ons/files/Children_and_AIDS_Fourth_Stocktaking_Report_EN_12 0209.pdf. Accessed 6 January 2010.

[45] Desgrées-du-Loû A, Brou H, Djohan G, Tijou-Traoré A. Le refus du dépistage VIH prénatal: étude de cas à Abidjan (Côte d'Ivoire) Santé 2007; 17(3): 133-41.

[46] WHO. Guide to the council and HIV testing to health workers Genève: 2007. Available at : http://whqlibdoc.who.int/publications/ 2007/9789242595567_fre.pdf

[47] Perez F, Zvandaziva C, Engelsmann B, Dabis F. Acceptability of routine HIV testing ("opt-out") in antenatal services in two rural districts of Zimbabwe. J Acquir Immune Defic Syndr 2006; 41(4): 514-20.

[48] Chandisarewa W, Stranix-Chibanda L, Chirapa E, Miller A, Simoyi M, Mahomva A. Routine offer of antenatal HIV testing ("opt-out" approach) to prevent mother-to-child transmission of HIV in urban Zimbabwe. Bull World Health Organ 2007; 85(11): 843-50.

[49] Kowalczyk J, Jolly P, Karita E, Nibarere JA, Vyankandonder J, Salihu H. Voluntary counseling and testing for HIV among pregnant women presenting in labor in Kigali, Rwanda. J Acquir Immune Defic Syndr 2002; 31(4): 408-15.

[50] Celetano DD. Is HIV screening in the labour and delivery unit feasible and acceptable in low income settings? PLoS Med 2008; 5(5): e107.

[51] Bajunirwe F, Muzoora M. Barriers to the implementation of programs for the prevention of mother-to-child transmission of 
HIV: a cross-sectional survey in rural and urban Uganda. AIDS Res Ther 2005; 2(10): 1-7.

[52] Perez F, Orne-Gliemann J, Mukotekwa T, et al. Prevention of mother to child transmission of HIV: evaluation of a pilot programme in a district hospital in rural Zimbabwe. BMJ 2004; 329(7475): 1147-50.

[53] Homsy J, King R, Malamba SS, Opio C, Kalamya JN, Mermin J. The need for partner consent is a main reason for opting out of routine HIV testing for prevention of mother-to-child transmission in a rural Ugandan hospital. J Acquir Immune Defic Syndr 2007; 44(3): 366-69.

[54] Painter T. Voluntary counseling and testing for couples: a highleverage intervention for HIV/AIDS prevention in sub-Saharan Africa. Soc Sci Med 2001; 53(11): 1397-411.

[55] Farquhar C, Kiarie JN, Richardson BA, et al. Antenatal couple counseling increases uptake of interventions to prevent HIV-1 transmission. J Acquir Immune Defic Syndr 2004; 37(5):1620-26.

[56] Semrau K, Kuhn L, Vwalika C, et al. Women in couples antenatal HIV counseling and testing are not more likely to report adverse social events. AIDS 2005; 19(6): 603-9.

[57] De Cock KM, Fowler MG, Mercier E, et al. Prevention of motherto-child HIV transmission in resource-poor countries: translating research into policy and practice. JAMA 2000; 283(9): 1175-82

[58] Breastfeeding and HIV International Transmission Study Group. Late postnatal transmission of HIV-1 in breast-fed children: An individual patient data meta-analysis. J Infect Dis 2004; 189(12): 2154-66.

[59] Leroy V, Karon JM, Alioum A, et al. Postnatal transmission of HIV-1 after a maternal short-course zidovudine peripartum regimen in West Africa. AIDS 2003; 17(10): 1493-501.

[60] Taha TE, Hoover DR, Kumwenda NI, et al. Late postnatal transmission of HIV-1 and associated factors. J Infect Dis 2007; 196(1): 10-14.

[61] Coovadia HM, Rollins NC, Bland RM, et al. Mother-to-child transmission of HIV-1 infection during exclusive breastfeeding in the first 6 months of life: an intervention cohort study. Lancet 2007; 369(9567): 1107-16.

[62] Becquet R, Bequet L, Ekouevi DK, et al. Two-year morbiditymortality and alternatives to prolonged breast-feeding among children born to HIV-infected mothers in Côte d'Ivoire. PLoS Med 2007; 4(1) : 139-41.

[63] Desclaux A and Taverne B. Allaitement et VIH en Afrique de l'Ouest. De l'anthropologie à la santé publique. Paris, KARTHALA, 2000. 556 p. Available at : http://classiques.uqac.ca/ contemporains/Desclaux_alice/allaitement_et_VIH/allaitement_et_ VIH.pdf. Accessed 7 January 2010.

[64] Bahl R, Frost C, Kirkwood BR, et al. Infant feeding patterns and risks of death and hospitalization in the first half of infancy: multicentre cohort study. Bull World Health Organ 2005; 83(6): 418-26.

[65] Kilewo C, Karlsson K, Ngarina M, et al. Prevention of mother-tochild transmission of HIV-1 through breastfeeding by treating mothers prophylactically with triple antiretroviral therapy in Dar es Salaam, Tanzania - the MITRA PLUS study. In: The Third Conference on HIV Pathogenesis and Treatment. Rio De Janeiro, Brasil, 2005. Available at: http://www.aegis.com/conferences/ iashivpt/2007/TUAX101.pdf

[66] Six Week Extended-Dose Nevirapine (SWEN) Study Team. Extended-dose nevirapine to 6 weeks of age for infants to prevent HIV transmission via breastfeeding in Ethiopia, India, and Uganda: an analysis of three randomised controlled trials. Lancet 2008; 372(9635): 300-13.

[67] Moorthy A, Gupta A, Bhosale R, et al. Nevirapine resistance and breast-milk HIV transmission: effects of single and extended-dose nevirapine prophylaxis in subtype C HIV-infected infants. PLoS One 2009; 4(1):1-8.

[68] Chasela C, Hudgens M, Jamieson D, et al. Both maternal HAART and daily infant nevirapine (NVP) are effective in reducing HIV-1 transmission during breastfeeding in a randomized trial in Malawi: 28-week results of the Breastfeeding, Antiretroviral and Nutrition (BAN) Study. In: The $5^{\text {th }}$ IAS Conference on HIV Pathogenesis and Treatment. Cape Town, South Africa, 2009. Abstract WELBC103.

[69] Taha TE, Kumwenda J, Cole SR, et al.Postnatal HIV-1 transmission after cessation of infant extended antiretroviral prophylaxis and effect of maternal highly active antiretroviral therapy. J Infect Dis 2009; 200(10): 1490-7.

[70] Giuliano M, Guidotti G, Andreotti M, et al. Triple antiretroviral prophylaxis administered during pregnancy and after delivery significantly reduces breastmilk viral load: a study within the drug resource enhancement against AIDS and malnutrition program. J Acquir Immune Defic Syndr 2007; 44(3): 286-91.

[71] Lehman DA, Chung MH, John-Stewart GC, et al. HIV-1 persists in breastmilk cells despite antiretroviral treatment to prevent motherto-child transmission. AIDS 2008; 22(12): 1475-85.

[72] Kesho Bora Study Group. Triple-antiretroviral prophylaxis during pregnancy and breastfeeding compared to short-ARV prophylaxis to prevent mother-to-child transmission of HIV-1: the Kesho Bora randomized controlled clinical trial in five sites in Burkina Faso, Kenya and South Africa. The $5^{\text {th }}$ IAS Conference on HIV Pathogenesis and Treatment. Cape Town, South Africa, 2009. Abstract LBPEC01.

[73] Thorne C, Newell ML. Safety of agents used to prevent mother-tochild transmission of HIV: is there any cause for concern? Drug Saf 2007; 30(3): 203-13.

[74] World Health Organisation. Rapid advice: use of antiretroviral drugs for treating pregnant women and preventing HIV infection in infants, November 2009. Available at: http:/www.who.int/ hiv/pub/mtct/rapid_advice_mtct.pdf Accessed the 28 January 2010.

[75] Bunnell R, Mermin J, De Cock K. HIV Prevention for a Threatened Continent. Implementing positive prevention in Africa JAMA 2006; 2 96(7): 855-8.

[76] Manga NM, Diop SA, Ndour CT, Dia NM, Mendy A, Coudec M et al. Dépistage tardif de l'infection à VIH à la clinique des maladies infectieuses de Fann, Dakar : circonstances de diagnostic, itinéraire thérapeutique des patients et facteurs déterminants. Méd Malad Infect $2009 ; 39(2): 95-100$.

[77] World Health Organisation and UNAIDS. Guidance on providerinitiated HIV testing and counselling in health facilities. May 2007. Geneva: World Health Organisation. Available at: http://www.who. int/hiv/pub/vct/pitc2007/en/. Accessed 7 January 2010.

[78] Le $\mathrm{Vu} \mathrm{S}$. Le dépistage sauf avis contraire. INVS 2007, Transcriptase, $\mathrm{n}^{\circ} 131$. Available at: http://www.pistes.fr/ transcriptases/131_565.htm. Accessed 7 January 2010.

[79] Wanyenze RK, Nawavvu C, Namale AS, et al. Acceptability of routine HIV testing and counseling and HIV seroprevalence in two large Ugandan hospitals. Bull World Health Organ 2008 ; 86 : 241 320 .

[80] Menzies N, Abang B, Wanyenze R, et al. The costs and effectiveness of four HIV counseling and testing strategies in Uganda. AIDS 2009; 23(3): 395-401.

[81] Mkwanazi NB, Patel D, Newell M-L, et al. Rapid Testing May Improve Uptake of HIV Testing and Same Day Results in a Rural South African Community: A Cohort Study of 12,000 Women. PLoS One 2008; 3(10): 1-5.

[82] Desgrées-du-Loû A, Orne-Gliemann J. Couple-centred testing and counselling for HIV serodiscordant heterosexual couples in subSaharan Africa. Reprod Health Matters 2008; 16(32): 151-61.

[83] Medley A, GarciaMoreno C, McGill S, Maman S. Rates. barriers and outcomes of HIV serostatus disclosure among women in developing countries: implications for prevention of mother-tochild transmission programmes. Bull World Health Organ 2004; 82(4): 299-307.

[84] Van Damme L, Ramjee G, Alary M, et al. Effectiveness of COL1492, a nonoxynol-9 vaginal gel, on HIV-1 transmission in female sex workers: a randomised controlled trial. Lancet 2002; 360(9338):971-7.

[85] UNAIDS. Microbicides 2008 is closing in India. 2008. Available at: http://www.unaids.org/fr/KnowledgeCentre/Resources/Feature Stories/archive/2008/20080227-microbicides.asp Accessed the 7 January 2010

[86] Microbicide development Program. HIV 'prevention' gel PRO 2000 proven ineffective. December 14, 2009. Available at: http://www.mdp.mrc.ac.uk/archive.html Accessed 7 January 2010

[87] Gilliam PP, Straub DM. Prevention With Positives: A Review of Published Research, 1998-2008. J Assoc Nurses AIDS Care 2009; 20(2):92-109.

[88] Auvert B, Taljaard D, Lagarde E, Sobngwi-Tambekou J, Sitta R, Puren A. Randomized, Controlled Intervention Trial of Male Circumcision for Reduction of HIV Infection Risk. The ANRS 1265 Trial. PLoS Med 2005; 2(11): 1112-22. 
[89] Gray RH, Kigozi G, Serwadda D, et al. Male circumcision for HIV prevention in men in Rakai, Uganda: a randomised trial. Lancet 2007; 369(9562): 657-66.

[90] Bailey RC, Moses S, Parker CB, et al.. Male circumcision for HIV prevention in young men in Kisumu, Kenya: a randomised controlled trial. Lancet 2007; 369(9562): 643-56.

[91] Berer M. Male Circumcision for HIV Prevention: Perspectives on Gender and Sexuality. Reprod Health Matters 2007; 15(29): 45-8.

[92] Wawer, MJ, F Makumbi, G Kigozi, et al. Circumcision in HIVinfected men and its effect on HIV transmission to female partners in Rakai, Uganda: a randomised controlled trial. Lancet 2007; 374(9685): 229-37.

[93] UNAIDS. 2009. Operational guidance for scaling up male circumcision services for HIV prevention. Available at: http://www.who.int/hiv/pub/malecircumcision/op_guidance/en/inde x.html. Accessed 7 January 2010.

[94] Berer M. Male circumcision for HIV prevention: what about protecting men's partners? Reprod Health Matters 2008; 16(32): 171-5.

[95] Castilla J, del Romero J, Hernando V, Marincovich B, García S Rodríguez C. Effectiveness of highly antiretroviral therapy in reducing heterosexual transmission of HIV. J Acquir Immune Defic Syndr 2005; 40(1):96-101.

[96] Granich R, Gilks C, Dye C, De Cock K, Williams B. Universal HIV testing with immediate antiretroviral therapy as a strategy for elimination of HIV transmission: a mathematical model. Lancet 2009; 373(9657): 48-57.

[97] Garnett G, Baggaley R. Treating our way out of the HIV pandemic: could we, would we, should we? Lancet 2009; 373(9657): 9-11.

[98] De Cock K, Gilks C, Lo Y, Guerma T. Can antiretroviral therapy eliminate HIV transmission? Lancet 2009; 373(9657):7-9.

[99] Attia S, Egger M, Muller M, Zwahlen M, Low N. Sexual transmission of HIV according to viral load and antiretroviral therapy: systematic review and meta-analysis. Aids 2009; 23(11): 1397-404.

[100] Paxton LA, Hope T, Jaffe HW. Pre-exposure prophylaxis for HIV infection: what if it works? Lancet 2007; 370(9581):89-93.

[101] Peterson L, Taylor D, Roddy R, et al. Tenofovir disoproxil fumarate for prevention of HIV infection in women: a phase 2, double-blind, randomized, placebo-controlled trial. PLoS Clin Trials 2007; 2(5):1-9.

[102] Abbas UL, Anderson RM, Mellors JW. Potential Impact of Antiretroviral Chemoprophylaxis on HIV-1 Transmission in Resource-Limited Settings. PLoS One 2007; 2(9): 1-11.

[103] Rosengarten M, Michael $M$. The performative function of expectations in translating treatment to prevention:The case of HIV pre-exposure prophylaxis, or PrEP. Soc Sci Med 2009; 69: 104955.

[104] Laraqui CH, Tripodi D, Rahhali A, et al. Knowledge, practice, and behavior of health care workers confronted to AIDS and the occupational risk of HIV transmission in Morocco. Médecine et Maladies Infectieuses 2002; 32(6): 307-14.

[105] Lee R. Occupational transmission of bloodborne diseases to healthcare workers in developing countries: meeting the challenges. J Hosp Infect 2009; 72(4): 285-91.

[106] ANRS press report. Vaccin contre le VIH : un pas en avant. ANRS 2009. Available at: http://www.anrs.fr/index.php/anrs/VIHSIDA/Vaccin/Actualites/Vaccin-contre-le-VIH-un-pas-en-avant. Accessed 7 January 2010.

[107] Rerks-Ngarm S, Pitisuttithum P, Nitayaphan S, et al. Vaccination with ALVAC and AIDSVAX to Prevent HIV-1 Infection in Thailand. N Engl J Med 2009; 23(361): 2209-20.

[108] Dolin R, HIV vaccine Trial results - An opening for further research. N Engl J Med 2009; 23(361): 2279-80.

(C) Desgrées du Loû et al.; Licensee Bentham Open.

This is an open access article licensed under the terms of the Creative Commons Attribution Non-Commercial License (http://creativecommons.org/licenses/ by-nc/3.0/) which permits unrestricted, non-commercial use, distribution and reproduction in any medium, provided the work is properly cited. 